\title{
Graft factors as determinants of postoperative delirium after liver transplantation
}

\author{
D. Patrono ${ }^{1}$ (D) F. Rigo ${ }^{1} \cdot$ S. Bormida ${ }^{1} \cdot$ P. Berchialla ${ }^{2} \cdot$ L. Giordanengo $^{3} \cdot$ S. Skurzak ${ }^{4} \cdot$ R. Balagna $^{4} \cdot$ R. Romagnoli $^{1}$ (i)
}

Received: 31 May 2020 / Accepted: 7 September 2020 / Published online: 24 September 2020

(c) The Author(s) 2020

\begin{abstract}
Post-operative delirium (POD) is a frequent complication after surgery, occurring in $15-20 \%$ of patients. POD is associated with a higher complications rate and mortality. Literature on POD after liver transplantation (LT) is limited, with the few available studies reporting an incidence of $10-47 \%$. The aim of this study was analyzing pattern, risk factors and clinical impact of POD after LT. Data on donor and recipient characteristics, postoperative course and POD of consecutive adult LT recipients from March 2016 to May 2018 were prospectively collected and retrospectively analyzed. Risk factors for POD were analyzed using univariable logistic regression and Lasso regression. Kaplan-Meier method was used for survival analysis. 309 patients underwent LT during study period; 3 were excluded due to perioperative death. Incidence of POD was $13.4 \%(n=41)$. The median day of onset was 5th (IQR [4-7]) with a median duration of 4 days (IQR [3-7]). Several risk factors, related to the severity of liver disease and graft characteristics, were identified. Graft macrovesicular steatosis was the only factor independently associated with POD at multivariable analysis (OR 1.27, CI 1.09-1.51, $p=0.003$ ). POD was associated with a higher rate of severe postoperative complications and longer intensive care unit and hospital stay, but did not significantly impact on patient and graft survival. Incidence of POD after LT is comparable to that observed after general surgery and graft factors are strongly associated with its onset. These results help identifying a subset of patients to be considered for preventive interventions.
\end{abstract}

Keywords Cognitive impairment $\cdot$ Postoperative delirium $\cdot$ Surgical quality $\cdot$ Ageing $\cdot$ Outcomes $\cdot$ Liver transplantation

\section{Introduction}

Post-operative delirium (POD) is one of the most common postoperative complications. Delirium can be defined as a transient, mostly reversible organic-mental syndrome that includes confusion, cognitive impairment, decline of vigilance, increased or reduced psychomotor activity and

R. Romagnoli

renato.romagnoli@unito.it

1 General Surgery 2U-Liver Transplant Unit, A.O.U. Città della Salute e della Scienza di Torino, University of Turin, Corso Bramante 88-90, 10126 Turin, Italy

2 Department of Clinical and Biological Sciences, University of Turin, Turin, Italy

3 Regional Transplant Center, Unit of Medical Psychology for Transplantation, A.O.U. Città della Salute e della Scienza di Torino, Turin, Italy

4 Anesthesia and Intensive Care Service 2, A.O.U. Città della Salute e della Scienza di Torino, Turin, Italy a disturbed sleep-wake cycle [1]. Prevalence in the general population is around $1-2 \%$, whereas in hospitalized patients its incidence is $10-40 \%$, with values reaching $56 \%$ in elderly patients and up to $87 \%$ in patients admitted to intensive care units (ICU) [1-3]. Nowadays, more and more elderly patients are considered eligible for surgery and surgical units have become familiar with the peculiarities of the ageing organism and its response to surgical stress [4, 5]. Postoperative delirium has been associated with prolonged length of ICU and hospital stay and increased costs of care, morbidity and mortality [6-8]. As incidence of POD can be reduced with specific interventions, the rate of POD has been proposed as an indirect measure of the quality of surgical care [9].

Limited data are available about POD in the setting of liver transplantation (LT). Compared to the general population of surgical patients, LT patients are younger, more frequently affected by chronic disease and are treated with immunosuppressants and steroids. Therefore, knowledge on POD gathered in the general surgical population might not 
be directly applicable to them. It has been suggested that pathogenesis of POD presenting after LT is multifactorial: infections, organ failure, encephalopathy and neurotoxicity of immunosuppressants have all been called into question. Reported POD incidence in LT patients ranges from 10 to $47 \%$ [10-16]. Also in the setting of LT, POD has been associated with prolonged hospital and ICU stay, and increased mortality. Previous studies have linked POD to the use of antidepressant drugs before surgery, history of pre-LT portosystemic encephalopathy, alcohol abuse, retransplantation or high APACHE II score [10, 11, 13-16].

However, all available studies suffer from limited numerosity, lack a prospective diagnosis of POD using stringent criteria, or were performed and restricted to an ICU setting. As timely identifying patients at risk of developing POD is crucial to set up adequate precautionary interventions, the aim of this study was to analyze incidence, patterns and risk factors for POD after adult deceased-donor LT in a highvolume LT unit, using robust statistical methodology.

\section{Patients and methods}

\section{Study population and design}

This is a retrospective cohort study on prospectively collected data on 309 consecutive adult LT recipients transplanted at our Center in the period from March 2016 to May 2018 to identify incidence, pattern and risk factors of POD after LT. Diagnosis of POD was based on confusion assessment method (CAM) $[17,18]$ and was confirmed by a senior member of our dedicated team of transplant psychologists and psychiatrists who are in charge of pre-LT assessment and post-LT follow-up. In brief, patients matching POD diagnosis should present both changes of mental status characterized by acute onset and fluctuating course and inattention, and either disorganized thinking or an altered level of consciousness. For POD cases we also collected data concerning timing, duration, pharmacological treatment and associated clinical events (e.g. lines/drains/nasogastric tube self-removal, accidental falls, need for physical restraint measures, etc.). Brain imaging was not systematically obtained. For all patients, we collected data on pre-LT baseline patient characteristics (including history of alcohol abuse or hepatic encephalopathy), donor features, transplant operation (including number of packed red blood cells and other blood products units transfused, duration of surgery, end-procedure lactate) and postoperative period (including duration of mechanical ventilation, tacrolimus blood level, rejection episodes, graft function and other complications). Due to the retrospective observational nature of the study, approval by local ethics committee was not sought. All study procedures complied with the Declaration of Helsinki and the Declaration of Istanbul.

\section{Patient management}

Indication for LT was discussed during multidisciplinary team meetings. All patients were systematically assessed by a transplant psychologist or psychiatrist before entering the waiting list. In patients with a history of alcohol abuse, a minimum of 3-months abstinence was confirmed by ethyl glucuronide hair test.

LT transplant anesthetic protocol included sedation by sodium thiopental or propofol (as induction agents), sevoflurane (for anesthesia maintenance) and analgesia using sufentanil. Patients were monitored by the mean of Entropy ${ }^{\circledR}$ monitoring during surgery without specific targets unless the avoidance of values above 60 . None of the patient received any premedication. Postoperative analgesia was based on continuous infusion of intra-venous morphine (usual dose between $0.6-1.2 \mathrm{mg} /$ hour and stopped on postoperative day 3 or 4$)$ and paracetamol $(1000 \mathrm{mg} / 8 \mathrm{~h})$.

LT was performed as a rule using piggyback technique with inferior vena cava preservation. Veno-venous by-pass was never employed. In case there was a concern for hemostasis control at the end of LT operation, patients were treated with temporary abdominal packing and delayed abdominal wall closure ("open abdomen"), as previously described [19].

Immunosuppression was based on steroids $(1000 \mathrm{mg}$ methylprednisolone intra-operatively; $20 \mathrm{mg}$ methylprednisolone or prednisone from day 1, tapered over 3 months), tacrolimus (target level 8-10 $\mathrm{ng} / \mathrm{ml}$ ) and mycophenolate mofetil. Tacrolimus trough level was measured daily in inpatients and twice a week in outpatients during the first month. Induction with basiliximab (20 mg intra-operatively and on day 4) was administered in patients with autoimmune or cholestatic liver disease.

All patients were admitted to ICU after LT and discharged to the transplant ward based on clinical course and bed availability. After discharge from the hospital, they were followed-up at our outpatient clinic.

\section{Definitions}

Early allograft dysfunction was defined according to the criteria proposed by Olthoff et al. [20]. Postreperfusion syndrome (PRS) was defined as a drop in mean arterial pressure $\geq 30 \%$ from baseline for at least one minute within 5 min from graft reperfusion [21]. Severity of PRS was graded according to Hilmi et al. as mild or severe, this last being characterized by severe hemodynamic instability with hypotension, asystole, hemodynamically significant arrhythmias, or prolonged and/or recurrent fibrinolysis [22]. Acute 
kidney injury (AKI) was defined and graded according to 2012 KDIGO guidelines [23]. Postoperative complications were graded according to Clavien-Dindo classification [24]. Prognostic scores, including model for-end stage liver disease (MELD), donor age * MELD (D-MELD), and donor risk-index (DRI), were calculated using formulae from the original papers $[25,26]$.

\section{Statistical analysis}

Continuous variables are reported as median and interquartile range (IQR). Categorical variables are reported as number and percentage. Pre-transplant patient characteristics, donor and transplant features, as well as outcomes were compared between patients who developed POD and controls. A stratified descriptive analysis was initially performed using POD as a grouping variable. The Mann-Whitney, Chi-square test and Fisher's exact tests were used to compare continuous and categorical variables, as appropriate. To identify variables associated with POD, univariable and multivariable logistic regression using least absolute shrinkage and selection operator (Lasso) method [27] were used. Survival analysis was performed using Kaplan-Meier method. For all analyses, the level of significance was set at 0.05 . All statistical analyses were performed with $R$ version 3.6.1. (R Foundation for Statistical Computing, Vienna, Austria. URL: https://www.R-project.org/).

\section{Results}

309 LT were performed during study period, 3 of which were excluded due to on-table patient death, yielding a cohort of 306 patients for analysis. Incidence of POD was $13.4 \%$ ( $n=41)$ (Fig. 1). Median timing of delirium onset and duration were 5 th postoperative day (4-7) and 4 days (3-7), respectively (Fig. 2). POD was associated with an accidental fall in $3(7.3 \%)$ patients, with nasogastric tube self-removal in $2(4.9 \%)$ patients, with venous lines self-removal in 4 (9.8\%) patients and with the need for physical restraint measures in $8(19.5 \%)$ patients. Haloperidol and promazine were the most frequently administered treatment in $32(78 \%)$ and $15(36.6 \%)$ of cases, respectively. Five patients were administered a combination of two or more drugs (Table 1).

We observed several differences concerning baseline patient characteristics according to the development of POD (Table 2). In particular, patients who developed POD had lower pre-LT serum albumin ( $3.3 \mathrm{vs.} 3.4 \mathrm{gr} / \mathrm{dL}$ ) and sodium (137 vs. $140 \mathrm{mmol} / \mathrm{L})$ levels, and higher bilirubin level (2.2 vs. $1.6 \mathrm{mg} / \mathrm{dL}$ ). They were more frequently admitted in hospital $(9.8 \%$ vs. $3.8 \%)$ or ICU (9.8\% vs. $3.8 \%)$ before LT, were more frequently on life support $(9.8 \%$ vs. $1.9 \%)$ and had more frequently a history of hepatic encephalopathy $(36.6 \%$ vs $.18 .1 \%)$ or were encephalopathic at LT $(9.8 \%$ vs. $2.6 \%)$.

Patients in the POD group received a graft with a significant higher percentage of macrovesicular steatosis (3\% vs. $0 \%$ ), had higher levels of lactate at the end of LT (2.4 vs. $2.0 \mathrm{mmol} / \mathrm{L}$ ), a higher incidence of postreperfusion syndrome (24.4\% vs. $12.8 \%)$ and required more frequently temporary packing followed by a delayed second-look operation (19.5\% vs. 6.8\%). D-MELD was higher in POD
Fig. 1 Cumulative incidence plot of delirium after liver transplantation. Light red area represents $95 \%$ confidence interval

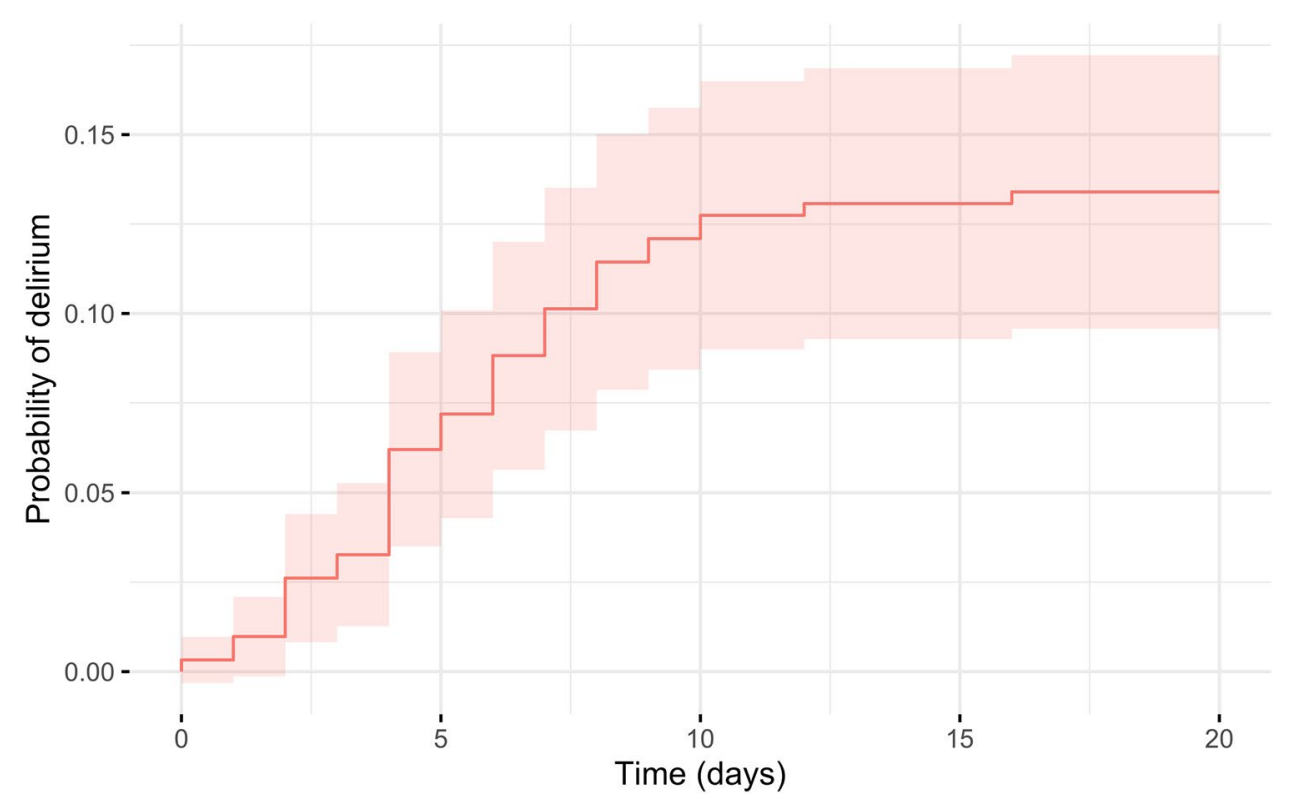




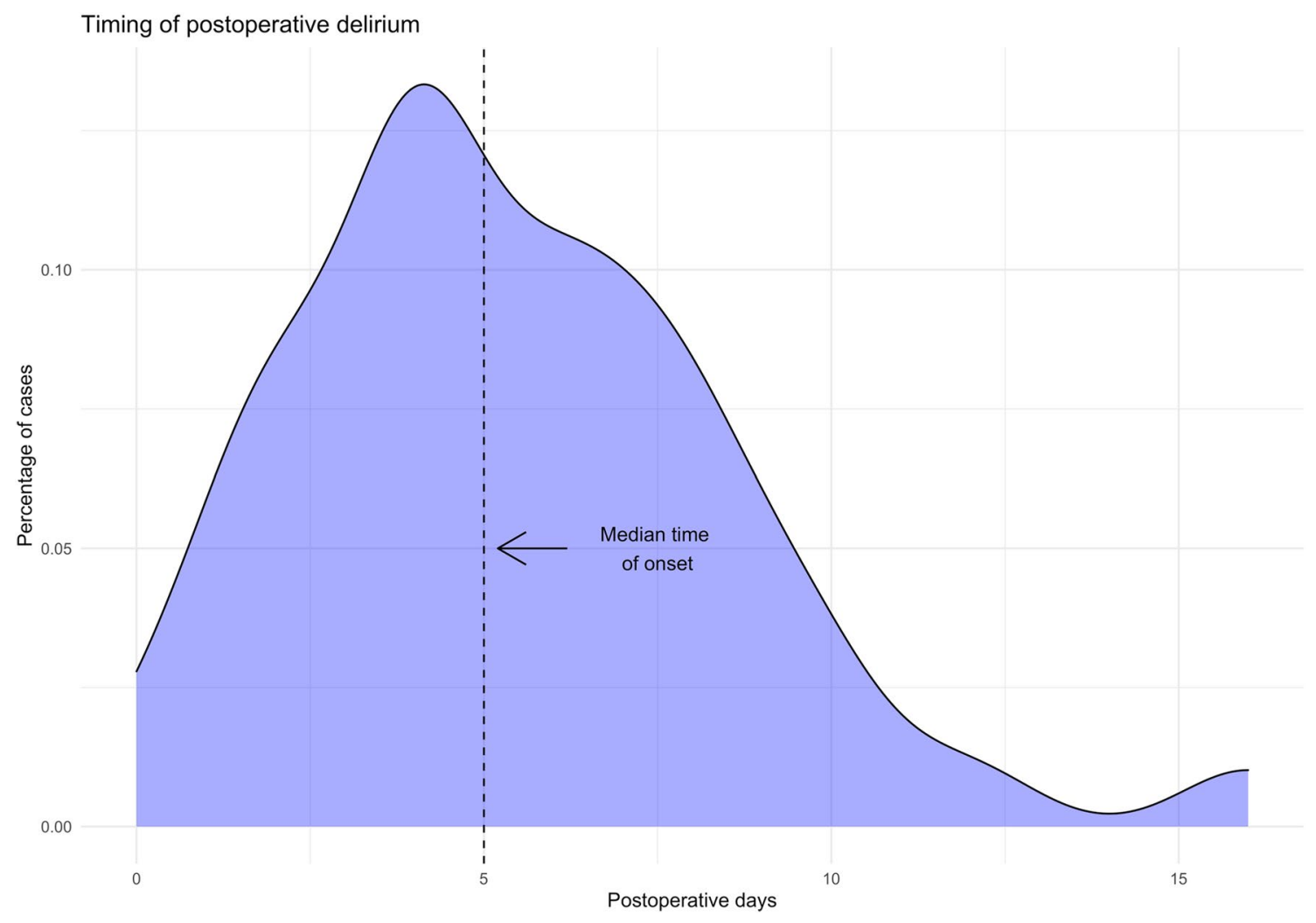

Fig. 2 Distribution of the day of onset of postoperative delirium cases. Vertical dotted line represents median time of onset

patients (968 vs. 731). For analysis purpose, D-MELD was dichotomized into a binary variable with cutoff $=1000$, which was the value associated with a steep raise in the risk of POD.

Postoperative outcomes (Table 3) were generally inferior in patients who developed POD, as they required mechanical ventilation for longer ( 26 vs. $15 \mathrm{~h}$ ) and had a higher rate of reoperation (22\% vs. $10.2 \%$ ) and grade IIIIV surgical complications (39\% vs. 16\%). Both hospital (18 vs. 11 days) and ICU stay (4 vs. 3 days) were prolonged in POD patients. Noteworthy, tacrolimus through levels were not significantly different during the first 15 postoperative days (Fig. 3).

At univariable logistic regression, several variables were associated with POD (Table 4). However, of the three variables included in the multivariable Lasso model (D-MELD $>1000$, history of encephalopathy and percentage of macrovesicular graft steatosis) only macrovesicular steatosis resulted significantly associated with POD (OR: 1.27 , CI: $1.09-1.51, p=0.003$ ). Indeed, distribution of macrovesicular steatosis was different in patients who developed POD, confirming its association with POD (Fig. 4).

Finally, survival analysis showed a trend towards inferior survival in patients developing POD (Fig. 5). However, this finding did not reach statistical significance.

\section{Discussion}

In this study, we linked POD delirium to several risk factors, confirming its multifactorial nature. The originality of our analysis is mainly represented by the inclusion of donor and transplant operation features in the analysis, which have been surprisingly neglected by previous literature on the subject (Table 5). To the best of our knowledge, this is the first study highlighting that donor factors, in particular the degree of graft macrovesicular steatosis, play a major role in determining the onset of POD after LT.

Looking at our data, the whole picture appears rather clear. POD incidence was higher in patients with signs of more severely compromised hepatic function (lower sodium and higher bilirubin levels, history of encephalopathy), poor nutritional status (lower albumin) and who were more frequently admitted to hospital or on life support prior to LT. These patients also showed higher incidence of postreperfusion syndrome and higher lactate levels at the end of transplant operation, which are early signs of impaired graft function [28, 29], a finding which in turn is in keeping with the association of POD with higher D-MELD and graft steatosis, this last being a well-known risk factor of poor graft function after LT [30]. Finally, patients suffering from POD also presented an increased rate of reoperation, had a 
Table 1 Characteristics and treatment of postoperative delirium after liver transplantation

\begin{tabular}{ll}
\hline Incidence & $41(13.4 \%)$ \\
Timing (postoperative day) & 5 th $(4$ th-7th) \\
Duration (days) & $4(3-7)$ \\
Associated clinical events & \\
Need for physical restraint measures & $8(19.5 \%)$ \\
Lines self-removal & $4(9.8 \%)$ \\
Accidental fall & $3(7.3 \%)$ \\
Nasogastric tube self-removal & $2(4.9 \%)$ \\
Treatment* & \\
Haloperidol & $32(78 \%)$ \\
Promazine & $15(36.6 \%)$ \\
Olanzapine & $4(9.7 \%)$ \\
Alprazolam & $4(9.7 \%)$ \\
Quetiapine & $3(7.3 \%)$ \\
Bromazepam & $3(7.3 \%)$ \\
Tiapride & $2(4.9 \%)$ \\
Lorazepam & $2(4.9 \%)$ \\
Amisulpride & $1(2.4 \%)$ \\
Aripiprazole & $1(2.4 \%)$ \\
Fluoxetine & $1(2.4 \%)$ \\
Lormetazepam & $1(2.4 \%)$ \\
Paroxetine & $1(2.4 \%)$ \\
Trazodone & $1(2.4 \%)$ \\
Zolpidem & $1(2.4 \%)$ \\
\hline
\end{tabular}

*5 patients were treated with a combination of two or more drugs

higher rate of severe postoperative complications and had longer ICU and hospital stay. Taken as a whole, these findings suggest that delirium represents a hallmark of a more deranged physiology before and after LT. Sicker patients receiving suboptimal grafts and suffering from postoperative complications would be at particularly high risk of developing POD. These different risk factors appear to be closely interlinked and likely act in an additive way. Surprisingly, multivariable analysis identified macrovesicular steatosis as the only variable independently associated with POD, suggesting that graft quality and function is pivotal in determining POD after LT. Although the minimal median difference in the degree of macrovesicular steatosis between study groups ( $0 \%$ vs. $3 \%$ ) could seem clinically insignificant, it should be noted that this difference reflected a completely different distribution of this variable, as shown in Fig. 4.

In part, the concept that POD rate can be higher in sicker patients has been suggested by previous studies. Lescot et al. [14] identified renal replacement therapy, history of encephalopathy and packed red blood cells transfusion as risk factors for POD, highlighting the relevance of intraoperative events, along with patient history. In a study on the incidence of POD in the setting of ICU after living donor LT by Wang et al. [16] patients with
APACHE II score $\geq 16$ or who were on mechanical ventilation for $\geq 5$ days were at higher risk of POD. The role of mechanical ventilation was confirmed by Bhattacharya et al. [10], who also found an association of POD with age, MELD, pre-LT hospital admission, history of alcohol abuse, urinary and pulmonary infection, and combined transplantation. Overall, these findings are in keeping with the hypothesis that POD may represent a response to surgical and physiological stress. In this view, POD could be frequently interpreted as an epiphenomenon of poor pre-LT status or a complicated postoperative course. Our analysis confirms this concept and takes it one step further by linking POD to graft factors, which are major determinants of postoperative course after LT.

Incidence of POD in our series was $13.4 \%$, which is lower as compared to previous series in the setting of LT [10-16], but comparable to the figure in the general surgical population $[9,31,32]$. This discrepancy is likely due to the different diagnostic modalities employed in previous studies, which is also reflected by the high variability of POD incidence across different series (Table 5). In contrast with previous studies $[10,11,16]$, we did not identify history of alcohol consumption before LT as a risk factor for LT. This can be explained by our rigorous selection policy for transplant candidates with alcoholic cirrhosis, who are closely followed-up during the evaluation process and while on the waiting list. Also, patients presenting with symptoms of abstinence from alcohol after LT were not classified as having POD unless they matched aforementioned diagnostic criteria for POD. Unfortunately, data about duration of alcohol abstinence before LT and concomitant use of other recreational drugs, which may have allowed fine-tuning our analysis, were not available.

As POD has been associated with reduced 1-year survival and long-term cognitive impairment [6-8], early identification of patients at increased risk for POD and implementation of mitigation or prevention strategies is of paramount importance. Environmental interventions like early discharge from ICU, resumption of oral feeding, lines and drains removal and free access to the ward for patient's families are widely adopted in our unit. Among pharmacological interventions, sedation with dexmedetomidine, an $\alpha 2$-adrenoceptor agonist, has shown promising results in the general population [33]. However, data are lacking in the setting of LT and, as dexmedetomidine has prevalent hepatic metabolism [34], its use could be problematic in the early postoperative course after LT.

Limitations of our study include its retrospective, singlecenter nature. As aforementioned, limited information about duration of alcohol abstinence, social background and associated use of other substances might have precluded finding a significant association of POD with history of alcohol abuse. 
Table 2 Patients, donor and transplant features by postoperative delirium

\begin{tabular}{|c|c|c|c|}
\hline & $\begin{array}{l}\text { No delirium } \\
(n=265)\end{array}$ & $\begin{array}{l}\text { Delirium } \\
(n=41)\end{array}$ & $p$ \\
\hline \multicolumn{4}{|l|}{ Patients features } \\
\hline Sex (male) & $199(75.1)$ & $29(70.7)$ & 0.69 \\
\hline Recipient age (years) & $55(51-60)$ & $57(53-59)$ & 0.45 \\
\hline Rank of LT & & & 0.15 \\
\hline First & $251(94.7)$ & $36(87.8)$ & \\
\hline Second & $14(5.3)$ & $5(12.2)$ & \\
\hline Weight $(\mathrm{kg})$ & $73(64-80)$ & $69(61-80)$ & 0.35 \\
\hline Height $(\mathrm{cm})$ & $170(165-175)$ & $170(164-175)$ & 0.90 \\
\hline Albumin (gr/dL) & $3.40(3.0-3.9)$ & $3.30(2.6-3.6)$ & 0.02 \\
\hline Sodium (mmol/L) & $140(136-142)$ & $137(134-141)$ & 0.01 \\
\hline Creatinine (mg/dL) & $0.84(0.72-1.04)$ & $0.89(0.79-1.12)$ & 0.21 \\
\hline Bilirubin (mg/dL) & $1.6(0.8-3.1)$ & $2.2(1.3-4.0)$ & 0.02 \\
\hline INR & $1.30(1.15-1.60)$ & $1.32(1.21-1.58)$ & 0.34 \\
\hline MELD & $12(9-7)$ & $14(11-17)$ & 0.27 \\
\hline Previous major abdominal surgery & $96(36.2)$ & $13(31.7)$ & 0.70 \\
\hline Renal replacement therapy before $\mathrm{LT}$ & $12(4.5)$ & $3(7.3)$ & 0.70 \\
\hline Status & & & 0.047 \\
\hline Home & $245(92.5)$ & $33(80.5)$ & \\
\hline Hospital & $10(3.8)$ & $4(9.8)$ & \\
\hline ICU & $10(3.8)$ & $4(9.8)$ & \\
\hline Life support & $5(1.9)$ & $4(9.8)$ & 0.02 \\
\hline History of encephalopathy before LT & $48(18.1)$ & $15(36.6)$ & 0.01 \\
\hline Encephalopathy at LT & $7(2.6)$ & $4(9.8)$ & 0.02 \\
\hline Ascites at LT & $93(35.1)$ & $19(46.3)$ & 0.22 \\
\hline History of alcohol abuse & $87(32.8)$ & $17(41.5)$ & 0.36 \\
\hline History of chronic HCV infection & $99(37.4)$ & $13(31.7)$ & 0.60 \\
\hline \multicolumn{4}{|l|}{ Donor and transplant features } \\
\hline Donor age (years) & $63(49-74)$ & $65(50-75)$ & 0.30 \\
\hline Graft weight (gr) & $1490(1290-1690)$ & $1450(1240-1840]$ & 0.97 \\
\hline Donor weight (kg) & $70(61-83)$ & $73(65-85)$ & 0.53 \\
\hline Macrovesicular steatosis (\%) & $0(0-5)$ & $3(0-15)$ & $<0.001$ \\
\hline Microvesicular steatosis (\%) & $5(0-22.5)$ & $10(0-20)$ & 0.33 \\
\hline DRI & $1.53(1.34-2.25)$ & $1.95(1.38-2.38)$ & 0.31 \\
\hline Total ischemia time (minutes) & $422(367-472)$ & $445(398-499)$ & 0.13 \\
\hline Packed red blood cells transfused (ml) & $1000(500-2250)$ & $1500(500-2750)$ & 0.23 \\
\hline Postreperfusion syndrome & $34(12.8)$ & $10(24.4)$ & 0.06 \\
\hline End-transplant lactate (mmol/L) & $2.00(1.50-2.90)$ & $2.40(1.90-3.70)$ & 0.04 \\
\hline Open abdomen & $18(6.8)$ & $8(19.5)$ & 0.02 \\
\hline
\end{tabular}

Data are expressed as number (\%) or median (interquartile range). LT liver transplantation, INR international normalized ratio, $I T U$ intensive care unit, $H C V$ hepatitis $\mathrm{C}$ virus, $D R I$ donor risk index

\section{Conclusion}

In conclusion, POD after LT is associated with severity of pre-LT hepatic disease and with graft features. In particular, graft steatosis in the only factor independently associated with POD. Incidence of POD is higher in patients suffering from severe complications and with a prolonged postoperative stay. Further studies are needed to identify strategies to prevent POD after LT. 
Table 3 Prognostic scores and postoperative variables by postoperative delirium

\begin{tabular}{llll}
\hline & $\begin{array}{l}\text { No delirium } \\
(n=265)\end{array}$ & $\begin{array}{l}\text { Delirium } \\
(n=41)\end{array}$ & $p$ \\
\hline D-MELD & $731(534-1026)$ & $968(649-1251)$ & 0.02 \\
D-MELD > 1000 & $0.26(0.44)$ & $0.46(0.50)$ & 0.006 \\
Mean Tac level day 1-7 (ng/ml) & $7.5(5.1-9.6)$ & $6.0(4.9-8.1)$ & 0.053 \\
Mean Tac level day 1-15 (ng/ml) & $7.5(5.5-9.1)$ & $6.7(5.6-7.7)$ & 0.25 \\
Duration of mechanical ventilation (hours) & $15(12-26)$ & $26(12-55)$ & 0.01 \\
Early allograft dysfunction & $81(30.6)$ & $18(43.9)$ & 0.13 \\
Biopsy proven rejection & $27(10.2)$ & $2(4.9)$ & 0.43 \\
Reoperation & $27(10.2)$ & $9(22.0)$ & 0.05 \\
Complications* & & & 0.004 \\
No or mild complications (grade I-II) & $214(81.0)$ & $24(58.5)$ & $16(39.0)$ \\
Severe complications (grade III-IV) & $43(16.0)$ & $1(2.4)$ & \\
Postoperative death (grade V) & $8(3.0)$ & $17(41.5)$ & 0.12 \\
Grade 2-3 acute kidney injury & $84(31.7)$ & $3(7.3)$ & 0.28 \\
Renal replacement therapy & $8(3.0)$ & $18(14-25)$ & 0.01 \\
Hospital length of stay (days) & $11(9-16)$ & $4(3-10)$ & 0.003 \\
ICU length of stay (days) & $3(2-59)$ &
\end{tabular}

Data are expressed as number (percentage) of median (interquartile range). *Clavien-Dindo classification. $D-M E L D$ donor age * model for end-stage liver disease score, $I C U$ intensive care unit

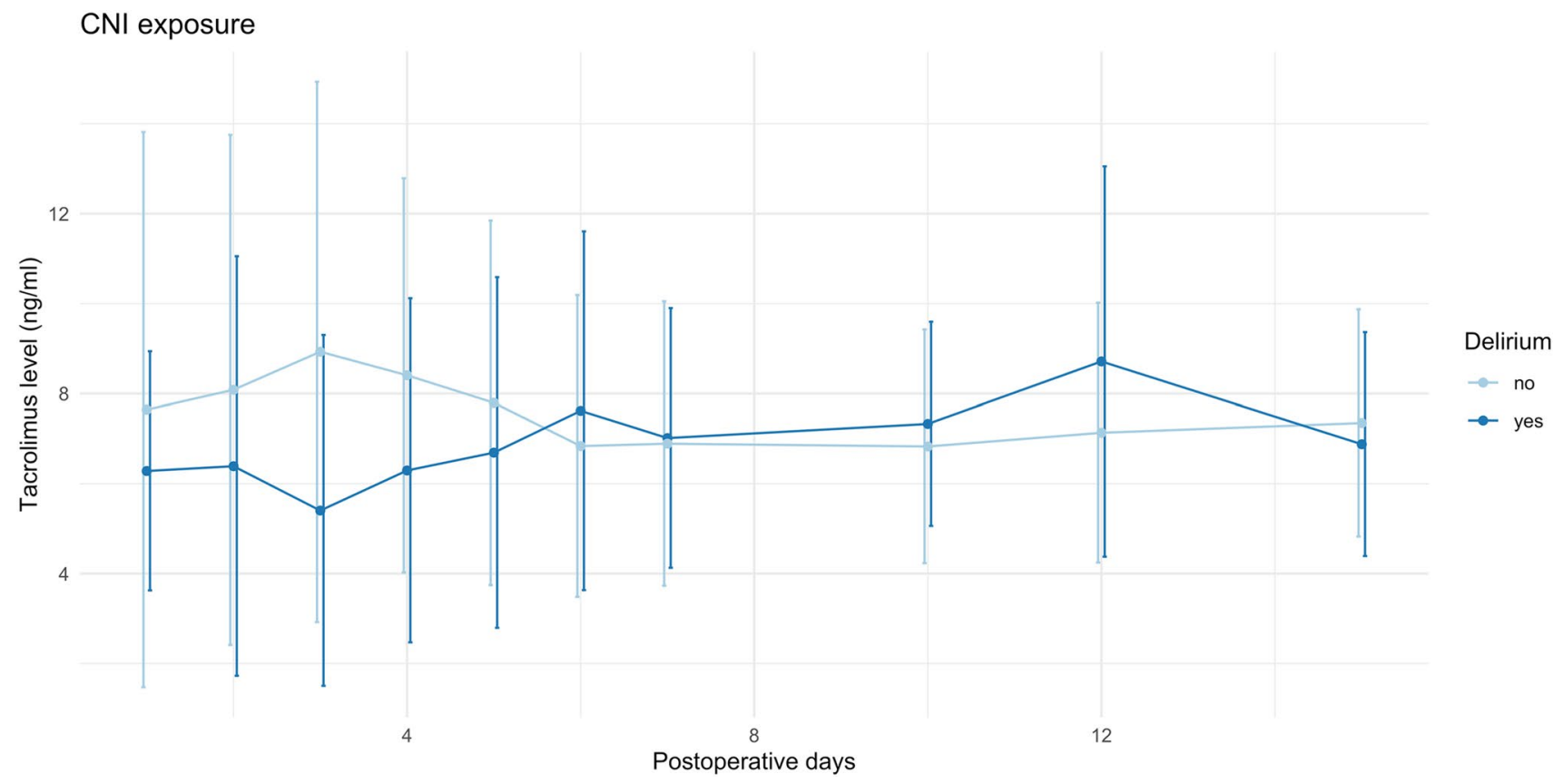

Fig. 3 Tacrolimus levels during first 15 postoperative days according to the presence of delirium. Dots represent mean values whereas vertical error bars represent \pm stadard deviation 
Table 4 Results of univariable logistic regression and multivariable Lasso regression

\begin{tabular}{|c|c|c|c|c|c|c|c|c|}
\hline & \multicolumn{4}{|c|}{ Univariable logistic regression } & \multicolumn{4}{|c|}{ Multivariable Lasso regression } \\
\hline & Effect & Lower 0.95 & Upper 0.95 & $p$ & Effect & Lower 0.95 & Upper 0.95 & $p$ \\
\hline Sex (female) & 1.248 & 0.602 & 2.584 & 0.551 & & & & \\
\hline Age (years) & 1.144 & 0.817 & 1.602 & 0.433 & & & & \\
\hline Retransplant & 2.490 & 0.846 & 7.327 & 0.098 & & & & \\
\hline Recipient weight (kg) & 0.864 & 0.548 & 1.363 & 0.530 & & & & \\
\hline Recipient height (cm) & 1.057 & 0.727 & 1.537 & 0.771 & & & & \\
\hline Albumin (g/dl) & 0.567 & 0.358 & 0.899 & 0.016 & & & & \\
\hline Sodium $(\mathrm{mmol} / \mathrm{L})$ & 0.625 & 0.444 & 0.880 & 0.007 & & & & \\
\hline Creatinine (mg/dl) & 0.963 & 0.844 & 1.099 & 0.577 & & & & \\
\hline Bilirubin (mg/dl) & 1.096 & 0.999 & 1.203 & 0.053 & & & & \\
\hline INR & 0.955 & 0.751 & 1.214 & 0.707 & & & & \\
\hline Previous abdominal surgery & 0.817 & 0.404 & 1.652 & 0.574 & & & & \\
\hline Dialysis & 1.664 & 0.449 & 6.171 & 0.446 & & & & \\
\hline Life support & 5.622 & 1.444 & 21.884 & 0.013 & & & & \\
\hline History of encephalopathy & 2.608 & 1.285 & 5.296 & 0.008 & 1.988 & 0.920 & 4.296 & 0.080 \\
\hline Encephalopathy at LT & 3.985 & 1.112 & 14.272 & 0.034 & & & & \\
\hline Ascites & 1.597 & 0.823 & 3.102 & 0.167 & & & & \\
\hline $\mathrm{HCV}$ & 0.778 & 0.385 & 1.573 & 0.485 & & & & \\
\hline Alcohol & 1.449 & 0.740 & 2.838 & 0.279 & & & & \\
\hline MELD & 1.224 & 0.851 & 1.762 & 0.276 & & & & \\
\hline D-MELD & 1.435 & 0.983 & 2.093 & 0.061 & & & & \\
\hline D-MELD > 1000 & 2.502 & 1.277 & 4.904 & 0.008 & 1.979 & 0.947 & 4.138 & 0.070 \\
\hline DRI & 1.358 & 0.754 & 2.445 & 0.307 & & & & \\
\hline Donor weight (kg) & 1.169 & 0.715 & 1.912 & 0.533 & & & & \\
\hline Donor height $(\mathrm{cm})$ & 1.214 & 0.729 & 2.021 & 0.456 & & & & \\
\hline Graft weight & 1.254 & 0.870 & 1.810 & 0.225 & & & & \\
\hline Macrovesicular steatosis (\%) & 1.283 & 1.092 & 1.507 & 0.002 & 1.286 & 1.092 & 1.514 & 0.003 \\
\hline Microvesicular steatosis (\%) & 1.051 & 0.742 & 1.489 & 0.779 & & & & \\
\hline Cold ischemia time (min) & 1.482 & 0.976 & 2.252 & 0.065 & & & & \\
\hline $\operatorname{PRBC}(\mathrm{ml})$ & 1.147 & 0.943 & 1.395 & 0.170 & & & & \\
\hline Surgery time (min) & 1.186 & 0.788 & 1.785 & 0.412 & & & & \\
\hline End-of-transplant lactate (mmol/L) & 1.258 & 0.945 & 1.676 & 0.116 & & & & \\
\hline Mechanical ventilation time (hours) & 1.127 & 1.022 & 1.242 & 0.016 & & & & \\
\hline ICU stay (days) & 1.418 & 1.134 & 1.772 & 0.002 & & & & \\
\hline Mean Tac level day 1-7 (ng/ml) & 0.537 & 0.283 & 1.021 & 0.058 & & & & \\
\hline Mean Tac level day $1-15(\mathrm{ng} / \mathrm{ml})$ & 0.676 & 0.374 & 1.223 & 0.196 & & & & \\
\hline
\end{tabular}

Analysis of variables associated with postoperative delirium after liver transplantation. INR international normalized ratio, $H C V$ hepatitis $\mathrm{C}$ virus, $M E L D$ model for end-stage liver disease, $D$-MELD donor age * MELD, DRI donor risk index, $P R B C$ packed red blood cells, ICU intensive care unit, Tac tacrolimus 
Fig. 4 Density distribution plot of macrovesicular steatosis according to the presence of delirium

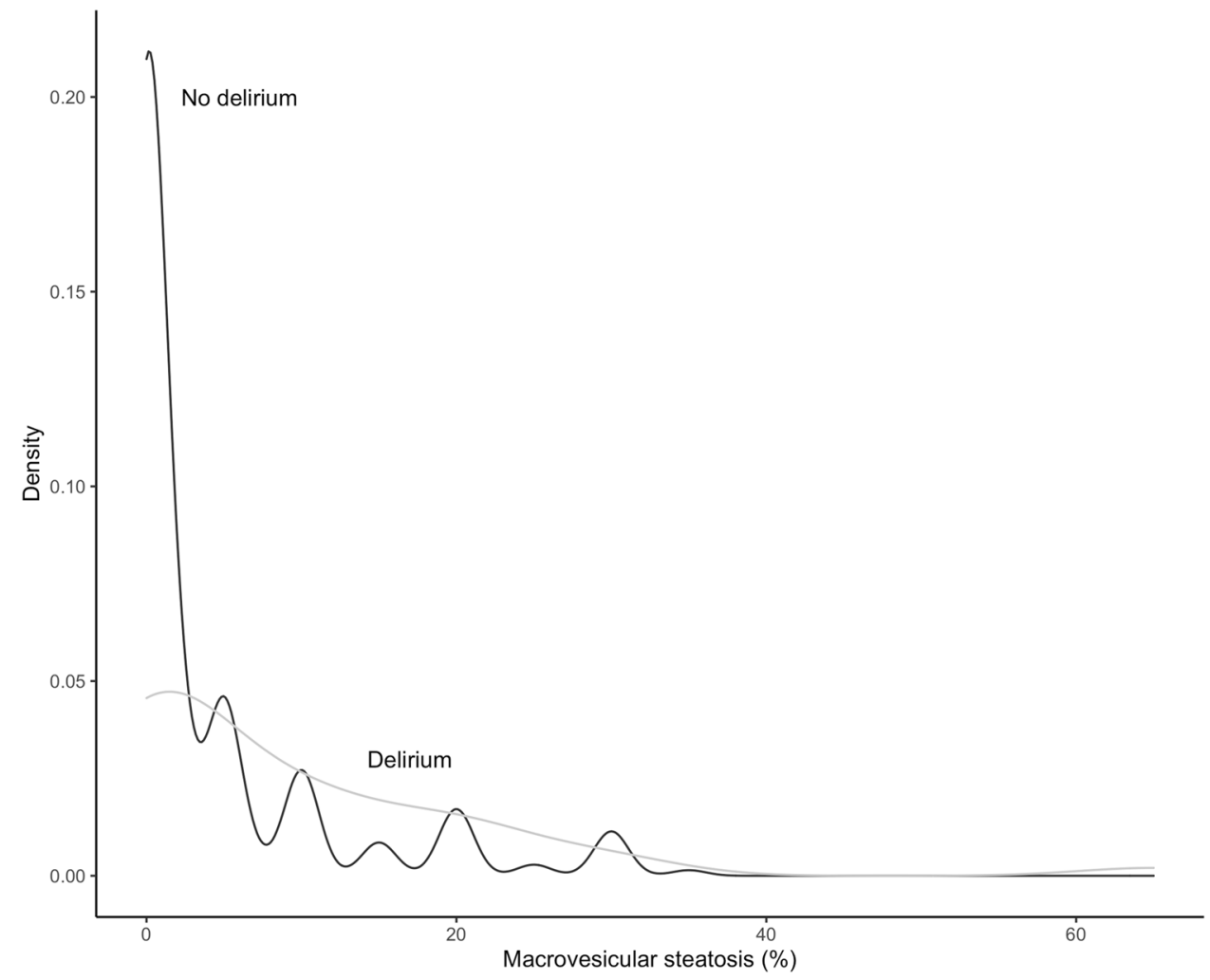

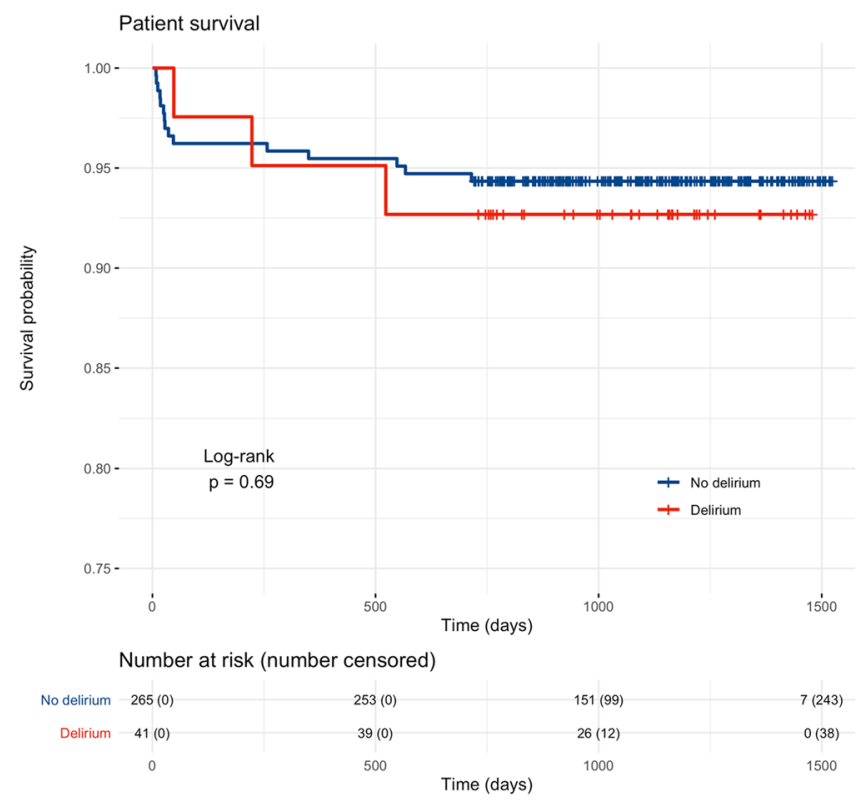

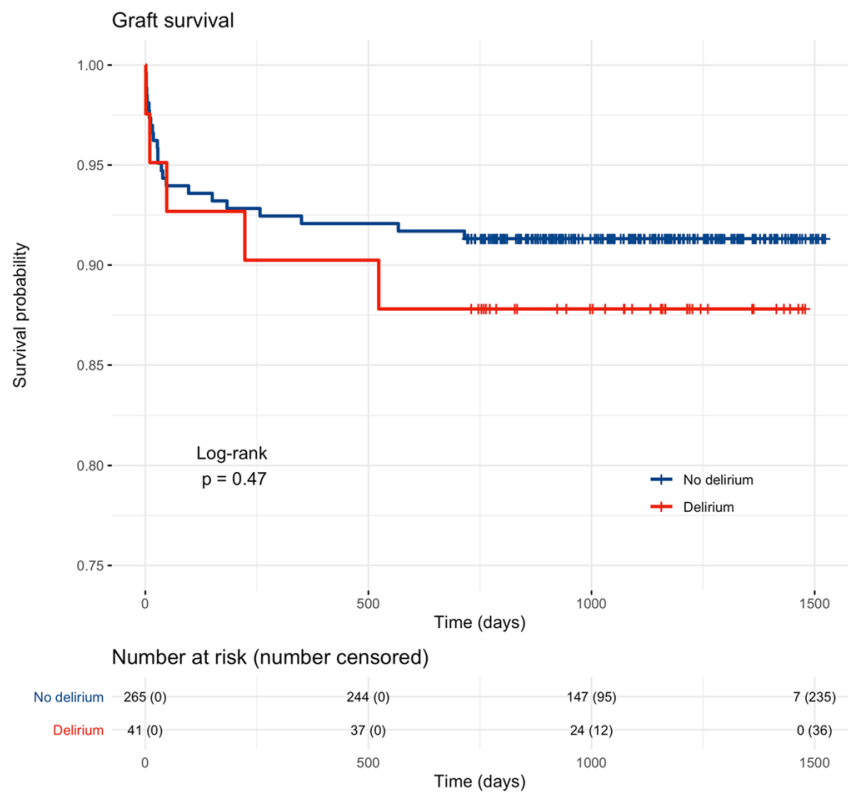

Fig. 5 Kaplan-Meier plots for patient and graft survival 
Table 5 Literature on postoperative delirium after liver transplantation

\begin{tabular}{|c|c|c|c|c|c|}
\hline Author, year & Setting & $N$ & Diagnosis & Incidence & Risk factors \\
\hline Buis et al. (2002) & Deceased-donor LT & 87 & Not specified & $25.5 \%$ & $\begin{array}{l}\text { Incidence of POD was } 48 \% \\
\text { in alcoholic patients ver- } \\
\text { sus } 16 \% \text { in HCV patients; } \\
\text { shorter duration of sobri- } \\
\text { ety, high pre-LT ammonia } \\
\text { and reduced creatinine } \\
\text { clearance associated with } \\
\text { POD }\end{array}$ \\
\hline Dhar et al. (2008) & Deceased-donor LT & 101 & Not specified & $27.7 \%$ & $\begin{array}{l}\text { Hepatic encephalopathy in } \\
\text { the immediate preopera- } \\
\text { tive period }\end{array}$ \\
\hline Chiu et al. (2009) & Deceased-donor LT & 30 & Psychiatric consultant & $\begin{array}{l}27.7 \% * \text { (among patients } \\
\text { referred for psychiatric } \\
\text { advice) }\end{array}$ & Not evaluated \\
\hline Lescot et al. (2013) & Deceased-donor LT, ICU & 281 & $\begin{array}{l}\text { POD suspicion raised } \\
\text { by attending nurse and } \\
\text { confirmed by senior } \\
\text { intensivist }\end{array}$ & $10 \%$ & $\begin{array}{l}\text { RRT before LT; history of } \\
\text { encephalopathy grade } \geq 2 \\
\text { PRBC transfusion }\end{array}$ \\
\hline Wang et al. (2014) & Living-donor LT, ICU & 78 & CAM-ICU & $47.4 \%$ & $\begin{array}{l}\text { History of alcohol abuse of } \\
\text { hepatic encephalopathy; } \\
\text { APACHE II score } \geq 16 ; \\
\text { orotracheal intuba- } \\
\text { tion } \geq 5 \text { days }\end{array}$ \\
\hline Bhattacharya et al. (2017) & $\begin{array}{l}\text { Deceased and living- } \\
\text { donor LT }\end{array}$ & 144 & $\begin{array}{l}\text { Delirium Observation } \\
\text { Screening scale } 8\end{array}$ & $25 \%$ & $\begin{array}{l}\text { Age; MELD; pre-LT } \\
\text { hospital admission; } \\
\text { alcohol abuse; duration } \\
\text { of mechanical ventilation; } \\
\text { urinary tract infection; } \\
\text { pneumonia; combined } \\
\text { transplantation }\end{array}$ \\
\hline Oliver et al. (2017) & Deceased-donor LT, & 181 & $\begin{array}{l}\text { Retrospective search of } \\
\text { electronic records }\end{array}$ & $21 \%$ & $\begin{array}{l}\text { Antidepressants and } \\
\text { encephalopathy prior } \\
\text { to LT }\end{array}$ \\
\hline
\end{tabular}

$N$ number of cases, $L t$ liver transplantation, $I C U$ intensive care unit, $P O D$ postoperative delirium, $R R T$ renal replacement therapy, $P R B C$ packed red blood cells, $C A M$ confusion assessment method, $A P A C H E$ acute physiology and chronic health disease classification system, $H C V$ hepatitis $\mathrm{C}$ virus, $M E L D$ model for end-stage liver disease

Author contributions DP, study concept and design, data analysis, manuscript drafting; FR, manuscript drafting and revision; SB, data collection, manuscript revision; $\mathrm{PB}$, data analysis, manuscript revision; LG, study concept, manuscript revision; SS, manuscript drafting and revision; RB, manuscript revision; RR, manuscript revision and supervision.

Funding Open access funding provided by Università degli Studi di Torino within the CRUI-CARE Agreement.

Availability of data and materials The data that support the findings of this study are available on request from the corresponding author. The data are not publicly available due to privacy restrictions.

\section{Compliance with ethical standards}

Conflict of interest The authors declare that they have no conflict of interest or competing interests.

Ethics approval Approval by the ethics committee was not sought due to the retrospective observational nature of the study.
Informed consent For this type of study, formal informed consent is not required.

Open Access This article is licensed under a Creative Commons Attribution 4.0 International License, which permits use, sharing, adaptation, distribution and reproduction in any medium or format, as long as you give appropriate credit to the original author(s) and the source, provide a link to the Creative Commons licence, and indicate if changes were made. The images or other third party material in this article are included in the article's Creative Commons licence, unless indicated otherwise in a credit line to the material. If material is not included in the article's Creative Commons licence and your intended use is not permitted by statutory regulation or exceeds the permitted use, you will need to obtain permission directly from the copyright holder. To view a copy of this licence, visit http://creativecommons.org/licenses/by/4.0/.

\section{References}

1. Neufeld KJ, Thomas C (2013) Delirium: definition, epidemiology and diagnosis. J Clin Neurophysiol 30:438-442 
2. Ely EW, Inouye SK, Bernard GR, Gordon S, Francis J, May L, Truman B, Speroff T, Gautam S, Margolin R, Hart RP, Dittus $R$ (2001) Delirium in mechanically ventilated patients: validity and reliability of the confusion assessment method for the intensive care unit (Cam-ICU). JAMA 286: 2703-2710

3. Roberts B, Rickard CM, Rajbhandari D, Turner G, Clarke J, Hill D, Tauschke C, Chaboyer W, Parsons R (2005) Multicentre study of delirium in ICU patients using a simple screening tool. Aust Crit Care 18: 6, 8-9, 11-4 Passim.

4. Etzioni DA, Liu JH, Maggard MA, Ko CY (2003) The aging population and its impact on the surgery workforce. Ann Surg 238:170-177

5. Hubbard RE, O'Mahony MS, Cross E, Morgan A, Hortop H, Morse RE, Topham L (2004) The ageing of the population: implications for multidisciplinary care in hospital. Age Ageing 33: 479-482.

6. Gleason LJ, Schmitt EM, Kosar CM, Tabloski P, Saczynski JS, Robinson T, Cooper Z, Rogers SO, Jr., Jones RN, Marcantonio ER, Inouye SK (2015) Effect of delirium and other major complications on outcomes after elective surgery in older adults. JAMA Surg 150: 1134-1140.

7. Robinson TN, Raeburn CD, Tran ZV, Angles EM, Brenner LA, Moss M (2009) Postoperative delirium in the elderly: risk factors and outcomes. Ann Surg 249:173-178

8. Saczynski JS, Marcantonio ER, Quach L, Fong TG, Gross A, Inouye SK, Jones RN (2012) Cognitive trajectories after postoperative delirium. N Engl J Med 367: 30-39.

9. Berian JR, Zhou L, Russell MM, Hornor MA, Cohen ME, Finlayson E, Ko CY, Rosenthal RA, Robinson TN (2018) Postoperative delirium as a target for surgical quality improvement. Ann Surg 268: 93-99.

10. Bhattacharya B, Maung A, Barre K, Maerz L, Rodriguez-Davalos MI, Schilsky M, Mulligan DC, Davis KA (2017) Postoperative delirium is associated with increased intensive care unit and hospital length of stays after liver transplantation. J Surg Res 207: 223-228.

11. Buis CI, Wiesner RH, Krom RA, Kremers WK, Wijdicks EF (2002) Acute confusional state following liver transplantation for alcoholic liver disease. Neurology 59:601-605

12. Chiu NM, Chen CL, Cheng AT (2009) Psychiatric consultation for post-liver-transplantation patients. Psychiatr Clin Neurosci 63:471-477

13. Dhar R, Young GB, Marotta P (2008) perioperative neurological complications after liver transplantation are best predicted by pre-transplant hepatic encephalopathy. Neurocrit Care 8: 253-258.

14. Lescot T, Karvellas CJ, Chaudhury P, Tchervenkov J, Paraskevas S, Barkun J, Metrakos P, Goldberg P, Magder S (2013) Postoperative delirium in the intensive care unit predicts worse outcomes in liver transplant recipients. Can J Gastroenterol 27: 207-212.

15. Oliver N, Bohorquez H, Anders S, Freeman A, Fine K, Ahmed E, Bruce DS, Carmody IC, Cohen AJ, Seal J, Reichman TW, Loss GE (2017) Post-liver transplant delirium increases mortality and length of stay. Ochsner J 17: 25-30.

16. Wang SH, Wang JY, Lin PY, Lin KH, Ko CJ, Hsieh CE, Lin HC, Chen YL (2014) Predisposing risk factors for delirium in living donor liver transplantation patients in intensive care units. PLoS ONE 9:E96676

17. Inouye $\mathrm{SK}$, Van Dyck $\mathrm{CH}$, Alessi CA, Balkin S, Siegal AP, Horwitz RI (1990) Clarifying confusion: the confusion assessment method. a new method for detection of delirium. Ann Intern Med 113: 941-948.

18. Shi Q, Warren L, Saposnik G, Macdermid JC (2013) Confusion assessment method: a systematic review and meta-analysis of diagnostic accuracy. Neuropsychiatr Dis Treat 9: 1359-1370.
19. Patrono D, Romagnoli R, Tandoi F, Maroso F, Bertolotti G, Berchialla P, Strignano P, Brunati A, Lupo F, Salizzoni M (2016) Peri-hepatic gauze packing for the control of haemorrhage during liver transplantation: a retrospective study. Dig Liver Dis 48: 414-422.

20. Olthoff KM, Kulik L, Samstein B, Kaminski M, Abecassis M, Emond J, Shaked A, Christie JD (2010) Validation of a current definition of early allograft dysfunction in liver transplant recipients and analysis of risk factors. Liver Transpl 16: 943-949.

21. Aggarwal S, Kang Y, Freeman JA, Fortunato FL, Pinsky MR (1987) Postreperfusion syndrome: cardiovascular collapse following hepatic reperfusion during liver transplantation. Transplant Proc 19: 54-55.

22. Hilmi I, Horton CN, Planinsic RM, Sakai T, Nicolau-Raducu R, Damian D, Gligor S, Marcos A (2008) The impact of postreperfusion syndrome on short-term patient and liver allograft outcome in patients undergoing orthotopic liver transplantation. Liver Transpl 14: 504-508.

23. Khwaja A (2012) Kdigo clinical practice guidelines for acute kidney injury. Nephron Clin Pract 120:C179-C184

24. Dindo D, Demartines N, Clavien PA (2004) Classification of surgical complications: a new proposal with evaluation in a cohort of 6336 patients and results of a survey. Ann Surg 240: 205-213.

25. Avolio AW, Cillo U, Salizzoni M, De Carlis L, Colledan M, Gerunda GE, Mazzaferro V, Tisone G, Romagnoli R, Caccamo L, Rossi M, Vitale A, Cucchetti A, Lupo L, Gruttadauria S, Nicolotti N, Burra P, Gasbarrini A, Agnes S, Donor-To-Recipient Italian Liver Transplant Study G (2011) Balancing donor and recipient risk factors in liver transplantation: the value of d-meld with particular reference to HCV recipients. Am J Transplant 11: 2724-2736.

26. Feng S, Goodrich NP, Bragg-Gresham JL, Dykstra DM, Punch JD, Debroy MA, Greenstein SM, Merion RM (2006) Characteristics associated with liver graft failure: the concept of a donor risk index. Am J Transplant 6: 783-790.

27. Mcneish DM (2015) Using lasso for predictor selection and to assuage overfitting: a method long overlooked in behavioral sciences. Multivar Behav Res 50:471-484

28. Golse N, Guglielmo N, El Metni A, Frosio F, Cosse C, Naili S, Ichai P, Ciacio O, Pittau G, Allard MA, Castaing D, Sac A, Cherqui D, Adam R, Vibert E (2019) Arterial lactate concentration at the end of liver transplantation is an early predictor of primary graft dysfunction. Ann Surg 270: 131-138.

29. Patrono D, Romagnoli R (2019) Postreperfusion syndrome, hyperkalemia and machine perfusion in liver transplantation. Transl Gastroenterol Hepatol 4:68

30. Kp C, Lee Dd, Cb T (2019) The "Skinny" on assessment and utilization of steatotic liver grafts: a systematic review. Liver Transpl 25:488-499

31. Ansaloni L, Catena F, Chattat R, Fortuna D, Franceschi C, Mascitti P, Melotti RM (2010) Risk factors and incidence of postoperative delirium in elderly patients after elective and emergency surgery. Br J Surg 97: 273-280.

32. De Castro SM, Unlu C, Tuynman JB, Honig A, Van Wagensveld BA, Steller EP, Vrouenraets BC (2014) Incidence and risk factors of delirium in the elderly general surgical patient. Am J Surg 208: 26-32.

33. Mo Y, Zimmermann AE (2013) Role Of dexmedetomidine for the prevention and treatment of delirium in intensive care unit patients. Ann Pharmacother 47: 869-876.

34. Weerink MAS, Struys M, Hannivoort LN, Barends CRM, Absalom AR, Colin P (2017) Clinical pharmacokinetics and pharmacodynamics of dexmedetomidine. Clin Pharmacokinet 56: 893-913.

Publisher's Note Springer Nature remains neutral with regard to jurisdictional claims in published maps and institutional affiliations. 